\title{
The prediction of the percentage of tattoo ink that is able to penetrate the stratum corneum in different
}

races

\section{Piotr Brzezinski ${ }^{1}$, Lorenzo Martini²}

${ }^{1}$ Institute of Biology and Environmental Protection, Pomeranian Academy, Slupsk, Poland, ${ }^{2}$ University of Siena, Department of Pharmaceutical Biotechnologies, Via A. Moro 2, 53100 Siena, Italy

Corresponding author: Lorenzo Martini, E-mail: martinil163@libero.it

\begin{abstract}
Background: Tattoos have always had an important role in ritual and tradition. Material and Methods: We have decided to scrutinize how much inks generally used by tattooists are able to penetrate the stratum corneum of the epidermis, keeping on account that it is always better pigments and carriers that constitute the ink do not penetrate deeper into the dermis, as ink can carry inside the human body bacteria and heavy metals or organic compounds too often very perilous to health. To examine this peculiar concern we have determined the percentage of seven common inks, employed by tattooists, that is able to link to the dead keratin of the stratum corneum of white,black and Asian individuals. We have collected samples of calluses of thee subjects, (black, white and Asiatic persons) praying an operator of an atelier of pedicure to give us fresh and just cut off calluses from different women and men. Results: Generally it can be asserted that the major penetration into the stratum corneum of the ink is observed in Asiatic persons, followed by White individuals and finally by Black subjects. Conclusion: The uptake increases according to the colours of the rainbow. Violet uptake by keratin of Stratum Corneum is minimum and Red uptake is maximum.
\end{abstract}

Key words: Tattooing; China ink; Heavy metals; Substantivity; Carbon black

\section{INTRODUCTION}

Tattooing has existed since 12,000 years $\mathrm{BC}$. The purpose of tattooing varies from culture to culture and its place on the time line.

Tattoos have always had an important role. In Borneo, women tattooed their symbols on their forearm indicating their particular skill. If a woman wore a symbol indicating she was a skilled weaver, her status as prime marriageable "item" was increased. Tattoos around the wrist and fingers were believed to ward away illness. Throughout history tattoos have signified membership in a clan or society.

In recorded history, the earliest tattoos can be found in Egypt during the time of the construction of the great pyramids. Around 2000 BC tattooing spread to China.
The Greeks used tattooing for communication among spies. Romans marked criminals and slaves. The Ainu people of western Asia used tattooing to show social status.

In the west, early Britons used tattoos in ceremonies. In Japan, at first, tattoos were used to mark criminals.

In the late 1700s, Captain Cook made several trips to the South Pacific. The people of London welcomed his stories and were anxious to see the art and artifacts he brought back. Returning form one of this trips, he brought a heavily tattooed Polynesian named Omai. He was a sensation in London. Soon, the upper- class were getting small tattoos in discreet places. For a short time tattooing became a fad.

What kept tattooing from becoming more widespread was its slow and painstaking procedure. Each puncture

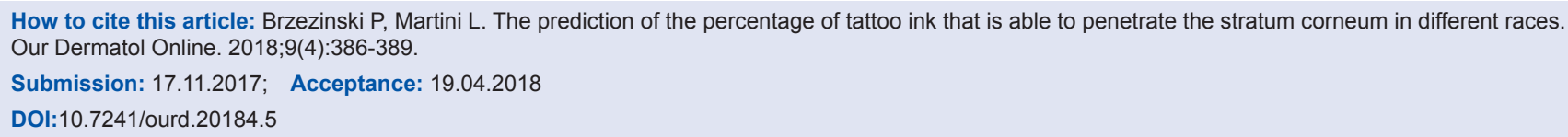


of the skin was done by hand the ink was applied. In 1891, Samuel O'Rtiely patented the first electric tattooing machine. It was based on Edison's electric pen which punctured paper with a needle point. The basic design with moving coils, a tube and a needle bar, are the components of today's tattoo gun. The electric tattoo machine allowed anyone to obtain a reasonably priced, and readily available tattoo. As the average person could easily get a tattoo, the upper classes turned away from it.

By the turn of the century, tattooing had lost a great deal of credibility. Tattooists worked the sleazier sections of town. Heavily tattooed people traveled with circuses and "freak Shows." In the 1930s tattooing shops embodied a star attraction for years in traveling circuses and faires.

With world war I, the flash art images changed to those of bravery and wartime icons.

In the 1920s, with prohibition and then the depression, Tattoing lost its appeal.

After world war II, tattoos became further denigrated by their associations with Marlon Brando type bikers and Juvenile delinquents. Tattooing had little respect in American culture. Then, in 1961 there was an outbreak of hepatitis and tattooing knew another epoch of momentaneous decadence.

In the late 1960s, the attitude towards tattooing changed.

Today, tattooing is making a strong comeback. It is more popular and accepted than it has ever been. Current artists combine the tradition of tattooing with their personal style creating unique and phenomenal body art. With the addition of new inks, tattooing has certainly reached a new plateau.

Humans have marked their bodies with tattoos for thousands of years. These permanent designssometimes plain, sometimes elaborate, always personal-have served as amulets, status symbols, declarations of love, signs of religious beliefs, adornments and even forms of punishment.

Nowaday it can be asserted that 1 in 5 adults have tattoos, up from $14 \%$ in last century.

Tattoo ink is composed of two components: the carrier and the pigment. The role of a carrier is to work as a suspension to keep the pigment evenly mixed and free from pathogens. Material safety data sheets (MSDSs) obtained from INTENZE inks, a popular tattoo ink retail company, show that their most common carriers consist of glycerin, water, isopropyl alcohol, and witch hazel. Either single use of one of these carriers or a mixture of similar carriers seems to be the common practice across most ink companies and artists [1].

It is notorious, regrettably, that manufacturers are not required to reveal their ingredients or conduct trials, and recipes may be proprietary. Professional inks may be made from iron oxides (rust), metal salts, plastics. Homemade or traditional tattoo inks may be made from china ink, soot, dirt, blood, or other ingredients.

Heavy metals used for colors include mercury (red); lead (yellow, green, white); cadmium (red, orange,yellow); nickel(black); zinc (yellow,white); chromium (green); cobalt (blue); aluminium (green, violet); titanium (white); copper (blue, green); iron (brown, red, black); and barium (white). Metal oxides used include ferrocyanide and ferricyanide (yellow, red, green, blue). Organic chemicals used include azochemicals (orange, brown, yellow, green, violet) and naptha-derived chemicals (red). Carbon (soot or ash) is also used for black. Other elements used as pigments include antimony, arsenic, beryllium, calcium, lithium, selenium, and sulphur [2] (Table I).

Violet Manganese Violet (manganese ammonium pyrophosphate),Various aluminum salts

\begin{tabular}{ll} 
Table 1: The main tattoo inks used throughout the world \\
\hline True Black & $\begin{array}{l}\text { Acrylic Resin, Pigment Black (Carbon Black), } \\
\text { Glycerin, Water, Isopropyl Alcohol, Witch Hazel }\end{array}$ \\
High White & $\begin{array}{l}\text { Acrylic Resin, Titanium Dioxide, Water } \\
\text { Red Cherry }\end{array}$ \\
& $\begin{array}{l}\text { Acrylic Resin, Pigment Red 210, Pigment Blue } \\
\text { 15, Glycerin, Water, Isopropyl Alcohol, Witch } \\
\text { Hazel }\end{array}$ \\
Hard Orange & $\begin{array}{l}\text { Acrylic Resin, Pigment Orange 13, Pigment Red } \\
\text { 210, Glycerin, Water, Isopropyl Alcohol, Witch } \\
\text { Hazel }\end{array}$ \\
Bowery Yellow & $\begin{array}{l}\text { Acrylic Resin, Pigment Yellow 65, Titanium Oxide } \\
\text { Acrylic Resin, Pigment Green, Glycerin, Water, } \\
\text { Isopropyl Alcohol, Witch Hazel }\end{array}$ \\
Baby Blue & $\begin{array}{l}\text { Acrylic Resin, Titanium Dioxide, Pigment Blue 15, } \\
\text { Glycerin, Water, Isopropyl Alcohol, Witch Hazel } \\
\text { Acrylic Resin, Pigment Violet 1, Titanium Oxide, } \\
\text { Geep Indigo }\end{array}$ \\
Glycerin, Water, Isopropyl Alcohol, Witch Hazel \\
Violet & $\begin{array}{l}\text { Manganese Violet (manganese ammonium } \\
\text { pyrophosphate),Various aluminum salts } \\
\text { Quinacridone, Dioxazine/carbazole }\end{array}$ \\
\hline
\end{tabular}


Quinacridone, Dioxazine/carbazole

A variety of medical issues can result from tattooing. Because it requires breaking the skin barrier, tattooing may carry health risks, including infection and allergic reactions [2-4]. Modern tattooists reduce such risks by following universal precautions, working with single-use items, and sterilising their equipment after each use.

Dermatologists have observed rare but severe medical complications from tattoo pigments in the body, and have noted that people acquiring tattoos rarely assess health risks prior to receiving their tattoos. Some medical practitioners have recommended greater regulation of pigments used in tattoo ink. The wide range of pigments currently used in tattoo inks may create unforeseen health problems.

Since tattoo instruments come in contact with blood and bodily fluids, diseases may be transmitted if the instruments are used on more than one person without being sterilised. However, infection from tattooing in clean and modern tattoo studios employing single-use needles is rare. With amateur tattoos, such as those applied in prisons, however, there is an elevated risk of infection.

\section{MATERIALS AND METHODS}

As we have referred before, we have prayed an operator of a boutique of pedicure to give us fresh and just cut off calluses of white,black and Asiatic people.

We have wighed the single samples (21 samples:7 of white person, 7 of black person, 7 of Asiatic persons) and we adjust the real quantity to $200 \mathrm{mg}$, so that each sample weighs about $200 \mathrm{mg}$.

We prepared 21 flasks $(50 \mathrm{ml})$ and fill them up with $0.03 \%$ ink solutions (the seven colours of the rainbow or of the painter's palette, that generally include black and white,even if we exluded these latter since white do not absorbe at UV spectrometry and black absorbes $99 \%$ at all the scales of wavelenght).

So we prepared sevens solutions containing seven tattoo inks and we had to insert the calluses in the seven solutions and shared in 21 flasks, in order to have a UV spectrum of each of everyone after 1 hour and after 12 hours.

It is well known that the following are the wavelenght the seven colours absorbe in the UV spectrometer.
Violet: 400 - $420 \mathrm{~nm}$; Indigo: 420 - $440 \mathrm{~nm}$; Blue: 440 - $490 \mathrm{~nm}$; Green: 490 - $570 \mathrm{~nm}$; Yellow: 570 - $585 \mathrm{~nm}$; Orange: 585 - $620 \mathrm{~nm}$; Red: 620 - $780 \mathrm{~nm}$.

Solutions $0.03 \%$ of the different inks are tested to evaluate the UV absorbance and we have confirmed that the peaks of the relative maximum absorbances were the following:

Violet: 0.8; Indigo: 0.9; Blue: 0.8; Green: 0.7; Yellow: 0.8; Orange: 0.9; Red: 0.9.

And this mean that at the corrisponding wavelength each colour reveals almost the maximum of absorbance (scale $0-1$ ).

Since it is possible, owing to the Lambert Beer's law to calculate the concentration $(\mathrm{m} / \mathrm{ml})$ of a known solution, we have extrapolated the 21 peaks of absorbances after one hour and after 12 hours.

In Table 2 it is observable the lowering of concentration of the single tattoo inks solutions after one and 12 hours, keeping on account that the original peaks of absorbances are those reffered before and that concentrations have been calculated thanks the Lambert Beer's law according to every measured peak of UV absorbances.

Table 2: Value of concentration of the single tattoo inks solutions after one and 12 hours.

\begin{tabular}{lcc}
\hline $\begin{array}{l}\text { Ink in the } \\
\text { diverse skin }\end{array}$ & $\begin{array}{c}\text { Concentrations } \\
\text { after } \mathbf{1} \text { hour }\end{array}$ & $\begin{array}{c}\text { Concentrations } \\
\text { after 12 hours }\end{array}$ \\
\hline Violet on A & 0.019 & 0.016 \\
Violet on W & 0.024 & 0.022 \\
Violet on B & 0.028 & 0.021 \\
Indigo on A & 0.019 & 0.017 \\
Indigo on W & 0.022 & 0.018 \\
Indigo on B & 0.024 & 0.021 \\
Blue on A & 0.022 & 0.020 \\
Blue on W & 0.023 & 0.021 \\
Blue on B & 0.025 & 0.022 \\
Green on A & 0.015 & 0.013 \\
Green on W & 0.017 & 0.014 \\
Green on B & 0.019 & 0.016 \\
Yellow on A & 0.013 & 0.010 \\
Yellow on W & 0.013 & 0.011 \\
Yellow on B & 0.018 & 0.016 \\
Orange on A & 0.012 & 0.009 \\
Orange on W & 0.014 & 0.010 \\
Orange on B & 0.016 & 0.012 \\
Red on A & 0.010 & 0.008 \\
Red on W & 0.012 & 0.009 \\
Red on B & 0.014 & 0.011 \\
\hline
\end{tabular}

Legends: Symbols A, W and B indicate the Asian, the White people and the Black ones 


\section{RESULTS}

It is clear that the concentrations of the solutions do increase from Asian skin, to White and then to Black skin.

This corresponds to a major penetration in Stratum corneum as the concentration calculated after 12 hours indicates the difference of the original concentration of tattoo ink and the final concentration that remains in solution and therefore it means that the minor is the concentration of the remnant solution, the major is the penetration in the Stratum Corneum.

It is noticeable, and suggestive, that the colour uptake from keratin of the Stratum Corneum, increases from Violet to Red inks.

In Table 3 it is possible to state the percentages of colour intake by keratin of S.C. of the single inks in Asian, White and Black skins.

\section{CONCLUSIONS}

We can assert what already has been referred by manifold AA $[5,6]$ that is that even in case of inks, the penetrabilty of the stratum corneum and epidermis is

Table 3: The percentages of colour intake by keratin

\begin{tabular}{lc}
\hline $\begin{array}{c}\text { Tattoo colour on } \\
\text { diverse skin }\end{array}$ & $\begin{array}{c}\text { Percentages of colour uptake } \\
\text { by keratin of S.C. }\end{array}$ \\
\hline Violet on A & 18 \\
Violet on W & 13 \\
Violet on B & 13 \\
Indigo on A & 17 \\
Indigo on W & 16 \\
Indigo on B & 14 \\
Blue on A & 15 \\
Blue on W & 13 \\
Blue on B & 13 \\
Green on A & 23 \\
Green on W & 21 \\
Green on B & 18 \\
Yellow on A & 30 \\
Yellow on W & 27 \\
Yellow on B & 18 \\
Orange on A & 33 \\
Orange on W & 30 \\
Orange on B & 25 \\
Red on A & 37 \\
Red on W & 33 \\
Red on B & 27 \\
\hline Legend: Symbls A, W and B & 13 \\
\hline
\end{tabular}

Legends: Symbols A, W and B indicate Asian, White and Black skins. major in Asiatic people, followed by White and Black persons.

Notwithstanding these confirmations, we have indivituated which is the maximum penetration (and thus the colour uptake by the keratin of Stratum Corneum) of each colour and results are surprising, since the uptake increases according to the colours of the rainbow.

Violet uptake by keratin of Stratum Corneum is minimum, Red uptake is maximum.

\section{STATEMENT OF HUMAN AND ANIMAL RIGHTS}

All procedures followed were in accordance with the ethical standards of the responsible committee on human experimentation (institutional and national) and with the Helsinki Declaration of 1975, as revised in 2008 .

\section{STATEMENT OF INFORMED CONSENT}

Informed consent was obtained from all patients for being included in the study.

\section{REFERENCES}

1. Maxim E, Higgins H, D'Souza L. A case of multiple squamous cell carcinomas arising from red tattoo pigment. Int J Womens Dermatol. 2017;3:228-30.

2. Gupta M. Pigmented contact dermatitis to p-paraphenylenediamine in a textile factory worker. Our Dermatol Online. 2017;8:424-6.

3. Martini L. Tattoo removal on an emancipist using Argoncryotherapy exploiting the Joule Thomson's coefficient to modulate the cooling effect. Our Dermatol Online. 2017;8(1e):e1.

4. Puri N, Puri N. A study on contact dermatitis to hair dye and henna. Our Dermatol Online. 2013;4:545-8.

5. Poon, Kelvin Weng Chun. In situ chemical analysis of tattooing inks and pigments: modern organic and traditional pigments in ancient mummified remains, University of Western Australia. 2008.

6. Kompaore F, Tsuruta H; In vivo differences between Asian, black and white in the stratum corneum barrier function. Int Arch Occup Environ Health. 1993;65(1 Suppl):S223-5.

Copyright by Piotr Brzezinski, et al. This is an open-access article distributed under the terms of the Creative Commons Attribution License,

which permits unrestricted use, distribution, and reproduction in any medium, provided the original author and source are credited.

Source of Support: Nil, Conflict of Interest: None declared. 